\title{
Challenges Confronting the Quality of Postgraduate Research Supervision and Its Effects on Time-to-Degree and Throughput Rates: A Case of a South African University
}

\author{
Lorna Holtman
}

Division for Postgraduate Studies, University of the Western Cape, P. Bag X17, Bellville 7535, South Africa, Iholtman@uwc.ac.za

\section{Geofrey Mukwada}

Division for Postgraduate Studies, University of the Western Cape, P. Bag X17, Bellville 7535, South Africa, gmukwada@gmail.com

\author{
Doi:10.5901/mjss.2014.v5n6p179
}

\begin{abstract}
Quality of academic research supervision is one of the major determinants of time-to-degree and throughput rates. Quality of supervision is key to the nature of guidance that the student receives from the supervisor. This research study was part of a bigger study that aimed at investigating the conditions that influence time-to-degree and throughput at the University of the Western Cape. A lime survey was conducted, requiring respondents to complete an emailed questionnaire online, while interviews were conducted with randomly selected academic research supervisors and administrators. The research study investigates the roles and responsibilities as well as the different approaches that supervisors adopt in nurturing their students. The study identified the constraints that undermine the quality of supervision and how these might be addressed from the viewpoint of the supervisors. The results indicate that postgraduate supervision takes a variety of forms and approaches and is largely determined by the research experience of the supervisors as well as how the supervisors themselves were supervised.
\end{abstract}

Keywords: postgraduate supervision, time-to-degree, throughput rates, mixed methods

\section{Introduction}

The quality of postgraduate supervision is one of the important factors influencing the time-to-degree and throughput rates at institutions of higher learning. Moreover, the quality of supervision is key to the nature of guidance that the postgraduate student receives from the supervisor. This statement is expressed by an academic in the following manner:

\begin{abstract}
I'm fairly familiar with the research, so I do have a fair sense of what quality constitutes. As I'm saying if it's the methodology that I'm not familiar with, I tend to co-opt another co-supervisor. The co-supervisor will then be co-opted for specific reasons, in other words I would task them with ...the methodology, does this methodology do that... that would be a quality assurance in that area. If it is a content area I don't believe as a supervisor that I have to read about the content area really, to be up to up rest with it, I do believe the student can teach the supervisor about the content if there's a specific content area. If it's really complicated I would co-opt let's say for instance someon very medical and only a medical experts could actually really do that, you could actually have somebody come on board as a cosupervisor or in some instances you can just ask them to comment on the proposal or the thesis (Postgraduate student supervisor).
\end{abstract}

The above direct quotation emanates from an interview with a supervisor when asked about what measures he had put in place to play the role of quality assuror in his supervision of postgraduate students. The response brings to the fore key questions related to quality of academic research supervision: How do supervisors perceive their roles and responsibilities? What supervisory approaches do supervisors adopt and what constraints do they face in their daily struggles in enhancing the research capacity of their students? and What solutions are considered by the supervisors as feasible when addressing the constraints? These questions helped us to identify factors that influence the quality of supervision. The assumption made here is that if supervisors understand their roles and responsibilities as well as the constraints that undermine those roles and responsibilities then they are in a better position to supervise their students, thus engendering quality supervision.

With reference to latter view, the quality of research supervision is critical in determining the successes or failures 
of PhD students in their research studies. According to Abiddin, Ismail, and Ismail (2011:207) supervision is "a central process for the successful completion of graduate programs. Partly, this stems from the diversity of expectations and notions that the supervisors have about their roles and responsibilities. Quality supervision is a multi-faceted phenomenon, not only embracing the knowledgeability of the supervisor but also his/ her ability to transmit the knowledge and skills to the student, the ability to induct the student into the research community, the ability to guide the student both socially and academically and in interpersonal skills.

In this paper we explore the quality of postgraduate student supervision as told by supervisors and we attempt to show how this affects time-to-degree among students at the University of the Western Cape.

\section{Conceptualising Quality Supervision}

Definitions of supervision abound. In the words of Abiddin, Ismail, and Ismail (2011:206) "supervision is an intensive, interpersonally focused one-to-one relationship between the supervisor and the student". On the other hand, Conrad (2003) conceives of supervision not only in terms of the strategies experienced in a close one-to-one relationship between the supervisor and the student, but also in relation to the supervisor's ability to bring research students together to enhance a scholarly research community. Irrespective of the view one holds about supervision, it is its quality that is at the heart of academic research discourse. The point here is that students, if given the opportunity would elect to be supervised by supervisors based on their perceived quality of supervision. Yet, quality of research supervision is not a straight forward issue but rather a complex and multi-faceted phenomenon encompassing a legion of factors.

It is argued that the quality of $\mathrm{PhD}$ research supervision is predicated on a wide range of factors, including the availability of financial support for research activities (Conrad, 2003),the social setting, the personalities of the supervisor and the student, the relationship between them, the supervisor's profundity of knowledge in the discipline area (Abiddin, Ismail, and Ismail, 2011), and language and cultural barriers amongst others (Doan and Yeoh, 2012). Quality of research supervision is of prime importance at the PhD level because PhD students need input in developing their critical and analytic ability in order to produce more original work of publishable standards (Abiddin, Ismail, and Ismail 2011).

Following the same line of argument, it is has been established that the supervisor's depth of knowledge in the discipline area of research is essential for PhD students in completing their research within candidature timeframe (Abiddin, Ismail, and Ismail 2011). For instance, it is reported that supervisor's knowledge of the discipline area of research is key for completion, with completion rates varying from $45 \%$ in arts and humanities to $70 \%$ in life sciences, with science completions being in the high $60 \%$ range in Canada. When supervisor-student roles are lucidly demarcated, the supervision process could be a very fascinating and enriching experience for both the supervisor and the student and the academic research community or environment as a whole. In defence of this claim Spear (2000) succinctly professes that:

To supervise research students is a great privilege. Students make a huge contribution to the academic research enterprise worldwide. They also provide a considerable effervescence to the academic environment of their host departments. The supervisory relationship often leads to lifelong friendships (p.18).

Against this background, the importance of the supervisor's role in enhancing quality supervision cannot be gainsaid. For this reason, helping students to develop skills in scholarly writing is one of the key roles of supervision (Heath, 2002). In most cases students who are studying in a second language or even third language (Holtzhausen, 2005) normally experience this problem and usually have difficulties in the use of correct grammar.

Certainly, difficulties on the part of the student in using correct grammar directly affect the quality of supervision, and, tangentially, the time-to-degree and throughput. This point is self-explanatory because the ability of the student to use grammar correctly to convey the message precisely as s/he intends to the supervisor is the chief objective communication process between the student and supervisor. In this regard, when the student fails to convey this message explicitly to the supervisor either verbally or in a written form, the entire communication process is compromised. For instance, a study conducted in Australia found that language barrier is one of the key challenges to quality graduate supervision(Doan and Yeoh, 2012). Supporting this point of view, Doan and Yeoh (2012) in a recent research study quotes a postgraduate student as s/he narrates the challenges s/he faces with respect to language.

At first, I found it unconfident when discussing with my supervisor. Sometimes it was so hard to make myself understood. It is not rare that I ask about one issue and he answers about another issue.

Consequently, Spear (2000:18) argues that the three essentials for effective supervision are "communication, communication, and communication"

Following from the preceding issue of communication in particular the use of language, Holtzhausen (2005) argues 
that supervisors need to be aware of four components of communicative competencies, namely grammatical competence (largely involving mastery of language), sociolinguistic competencies (appropriateness of meaning and forming rules of politeness), discourse competencies (ability to combine grammatical forms and meanings to achieve a unified spoken or written text) and strategic competence (the ability to compensate for lapses and breakdowns in communication - what second-language learners do to overcome the their deficiencies). Grant and Graham (1999) opioned that:

Like all university pedagogies at any particular historical moment, supervising practices are produced within the available educational discourses. These discourses are hidden sets of social rules and meanings, which offer particular subject positions for supervisors and student (p79).

In this context supervision constitutes a fundamental process of socialization. However, supervisors, particularly in Western universities, experience difficulties in understanding the message that second-language learners will be conveying, thus disrupting the process of socialization "of coming to terms with the writing requirements and academic culture of Western universities" (Woodward-Kron, 2007: 254). Mendoza (2007) maintains that doctoral students go through two socialization processes, simultaneously, one of which is related to the academic profession, and the other to their status as graduate students. While reporting their findings on research conducted in two Swedish industrial schools Salminen-Karlsson and Wallgren (2007: 80) noted: "A thesis is admittedly the end product of graduate education, but socialization into 'academic thinking' is an important part of the process, brought about by interaction with supervisors and peers." Similarly, regarding science as a discipline, Campbell (2003) maintains that socialization and enculturation are an integral aspect of what constitutes science. With respect to international graduate students in the UK, however, Wisker et al (2003: 93) claim that:

For international postgraduates, the difficulties of working in another working culture, a new social environment, are compounded by coping with tertiary literacy issues, that is, being able to fully articulate complex ideas and arguments in a second language to a level befitting that of the student's thought processes.

Research on international students by Heng-Yu et al (2008: 365) revealed that matriculation into a doctoral programme of study can be a difficult transition for many people, while students transitioning into graduate school have been shown to experience increased feelings of insecurity, decreased self-esteem and high levels of stress and anxiety. Heng-Yu et al indicated that one of the primary causes of anxiety amongst international students is that these students speak different languages and are also from different academic backgrounds.

Second, the inability of the student to produce quality work can be a challenge to both the student and the supervisor. In some instances students may end up doing courses that help them to understand the methods and techniques that they have to employ in their research, and in the process lengthen time-to-degree. Third, is poor turnover time, referring to situations when supervisors take too long to give their students feedback or to respond to their requests. In some cases feedback is infrequent and unreliable.

Fourth, is lack of sensitivity by supervisors when giving feedback. This normally leads to the undermining of the student's self esteem and discouragement. Mentoring can play an important role in academic socialization. Existing literature portrays research supervision as the most advanced level of teaching in the educational system or the process of fostering and enhancing learning, research and communication at the highest level (Morrison et al, 2007). However, for research supervision to function as a tool for socialization "mentors need to be able to exercise tolerance and respect for differences while facilitating their protégés' construction of values that were the product of informed, rational interdependence" (Blunt and Conolly, 2006) Mentoring itself "has become the subject of academic study and widespread experimentation, especially in the USA" (Jowett and Stead, 1994: 20). Thomas (2007: 178) argues that:

There is almost no institution nor environment in which mentoring is not discussed as a critical tool for personal, professional, and career development. Mentoring programs within industrial organizations are commonplace and they have a growing occurrence on college campuses... Perhaps it is expected then that at the graduate level, especially for doctoral students, that effective mentoring relationships flourish between graduate students and their major professors/ advisors.

In some cases, even prior to the student's candidature, there may already be a flourishing and close professional and/or personal relationship between the student and the supervisor (Boucher and Smyth, 2004). Mentoring is a key element of graduate education (Rose, 2005) and it is the most effective way to transfer skills and knowledge quickly and inspire loyalty in new employees to cooperate in an organization (Abiddin, 2006). The mentor can be an excellent source of ideas and "can serve as an informed reviewer of the student's work" (Cohen, 2002: 586). Cohen argues further that a 
mentor can be a trusted source for guidance on personal matters. This notion is supported by Mapesela and Wilkinson (2005) who maintain that there is need for a personalized mentorship approach in postgraduate research supervision.

In this context, mentoring provides academic student protégés with academic guidance, career development, personal guidance, and overall aid in the socialization of the graduate student (Thomas et al, 2007). As suggested by Kram (1985), cited in Humble (2006: 3) mentoring consists of two functions: career, preparing individuals for a career; and psychosocial, providing social support. "Mentors provide sponsorship, protection, exposure, visibility, counselling, acceptance, confirmation, and/ or coaching to their graduate students" (Rose, 2005: 53). Anderson et al (2006) suggest that the supervisor plays a gate-keeping role in maintaining academic standards. Taken from this angle mentoring helps students to develop life long skills and talent, involving "a deliberate pairing of a more skilled person with a lesser skilled or experienced one, with the agreed-upon goals of having the lesser skilled person grow and develop specific competencies" (Jowett and Stead, 1994: 21). Thomas et al (2007: 179), regard mentoring as "the act of providing guidance and support delivered from a mentor to a protégé", where more often a senior colleague provides support, feedback, information, and advocacy to a more junior and less experienced colleague. Jowett and Stead (1994: 25) argue that mentors need skills over and above their professional ones, especially about how to provide support to their students, thus making mentoring "a potentially valuable development vehicle in many contexts, not least within higher education."

Thomas et al (2007) observed that most definitions on mentoring agree that mentoring goes beyond mere career development, but includes the building of a strong personal relationship between the mentor and the mentee, which has an instrumental and psychological function. For the mentor to perform a functional role he/ she must be knowledgeable, experienced, visible and powerful and since not all faculty members have these attributes it follows also that they can't all be credible mentors (Thomas et al (2007). Other attributes that mentors must have include intelligence, integrity, ability, professional attitude, high personal standards, enthusiasm and a willingness to share accumulated knowledge (Abiddin, 2006). Alluding to this view Rose (2005) notes that the mentor is supposed to be a teacher, advisor and a guru. Fifth, is failure of supervisors to consult experienced colleagues on issues they are not sure of. Mullen (2001) proposed the Writing Process and Feedback (WPF) Model as an approach of assessing and teaching supervisees. The model provides a mechanism through which students constantly received feedback at all stages of the thesis. This model is akin to the one suggested by Hockey, 1996. Hockey, argues that in line with supervisory contracts, both the students and the supervisor have different considerations which must be matched within a supervisory relationship. Supporting this point, Abiddin, Ismail and Ismail (2011) indicate that good relationship between student and supervisor will ensure their research project is completed successfully.

\section{Research Methodology}

\subsection{Research Design}

The methodology adopted in this paper is theoretically informed. Following from the preceding discussion, quality of supervision is a multidimensional phenomenon and, thus, demands an encompassing research design capable of capturing the concept comprehensively. For this reason, a mixed methods research design is adopted in this study. By mixed methods is meant the combination of both qualitative and quantitative methods to collate, present and analyse data. The justification for adopting such a design is predicated on the idea that both methods have their weaknesses and strengthens. Therefore, combined in one single study, the weaknesses of one method will be complemented by the strengths of the other. In defence of this point, it is argued that mixed methods research provides a broader and credible understanding of the research problem than either qualitative or quantitative strategies alone (Tashakkori \& Teddlie, 2010 cited in Teye, 2012).

The combination of the methods will be in sequence. Qualitative data collection and analysis will precede quantitative data collection and analysis. What follows is a brief description of the instruments for qualitative data collection and analysis techniques used.

\subsection{Sampling}

For the qualitative part of the study, a convenient sampling method was employed. Participants in the quantitative study (103 respondents) were asked to indicate their readiness to participate in the interviews. Forty five supervisors agreed to be interviewed. For the quantitative part of the study, the alphabetical list of names of academics employed at UWC was obtained from the University database and random sampling delivered 200 names (approximately $50 \%$ of the full time 
academic staff complement in the 2009/2010 academic year). Some respondents indicated that they were not currently supervising students at the postgraduate level. They were excluded from the final list of respondents. Included in the final sample for the survey were supervisors who supervised both Masters and Doctoral students. The final number of respondents was 103 respondents.

\subsection{Qualitative data collection and analysis}

The collection of qualitative data were achieved through the use of interview schedules during in-depth interviews which were conducted with forty-five interviewees, including supervisors from all the departments within the university, while interviews were held with Heads of departments, Deans and Assistant deans. Each interview lasted about an hour on average. A phenomenological approach was used to guide the interviews. The key aspects of this approach are openness and depth (Wright et al, 2007). The interviews were open in the sense that they allowed questions to be guided by preceding questions in a snowball manner, while depth provided the means for probing individual interviewees until consensus and mutual understanding was reached about the phenomenon in question (Wright et al, 2007).

In addition, qualitative data collection involved the use of the case story approach or telling approach (Murphy et al, 2007). The adoption of this approach has been recommended by Holland (1989: 62) who argues that "stories have their own kind of power to engage the mind of the reader or listener. This power resides in the ability of narrative, as a distinct mode of cognitive functioning, to establish 'not truth, but verisimilitude'. Stories touch, in unpredictable and unpremeditated ways, the mind of the reader or listener, yielding new awareness and understanding of human experience."

\subsection{Quantitative data collection and analysis}

Quantitative data were collected through a lime survey. Lime survey is an online software tool that enables the automation of data collection and analysis. The questionnaire that was used in the survey is in Appendix II. The guide that was provided by Denicolo (2004) on how a questionnaire survey can be used in research on academic research supervision was applied. This was particularly useful in designing the questionnaire. Prior to use, the questionnaire (just like the interview schedule) was validated by accomplished researchers within the institution to ensure that it conformed to the required standards.

Data were exported to Statistical Package for Social Scientists (SPSS), and Microsoft Excel 2007, where more rigorous statistical analyses were performed. The results are presented in form of frequency tables and graphs.

\subsection{Ethical considerations}

Before the research proceeded, informed consent was obtained from the academic supervisors who were willing to participate in the study. Participants were informed about the purpose of the study, they were assured of anonymity and confidentiality. Furthermore, participants were informed about their right to withdraw from the study at any time. Ethical consent to conduct the study was approved by the University Ethics Committee.

\section{Research Results and Discussions}

The above cited supervisor is one of the postgraduate supervisors at UWC who has realized that problems related to quality of supervision are not a dyadic issue but an institutional issue that requires the involvement of other players apart from the supervisor and the student. In the above cited example the supervisor co-opts other supervisors whenever he realizes the limitations of his capabilities. However, supervisors' perceptions vary considerably regarding how supervisors at UWC perceive their roles and responsibilities, as well as the supervisory approaches that they adopt.

\subsection{Supervisors' perceptions of their roles and responsibilities}

Virtually all supervisors interviewed at UWC maintained that their role is to guide their students through the research process. Though a plethora terms were used to describe this process, we have classified these roles into three major categories, namely teaching, assessing and pastoral. However, it should be noted here that because of the interconnectedness of these roles we are only categorizing them for convenience.

Asked what the exact role of an academic research supervisor is one experienced academic research supervisor 
states:

Well, I think first and foremost, it is the responsibility of the supervisor to render support to the student. Are you referring to the student doing research and me supervising? Okay, to render the necessary academic support to the student. To give advice to assist whenever he or she has got a query or when they get stuck in the research process. And more specifically, I would say to guide them in their research methodology. I would say that they do research the proper way and that they come and have a scientifically sound document. That is what I see as my role and obviously I give advice and maybe feedback on the work that they submit and also to guide them into certain directions of research. And specifically, the available literature and help them cover as wide a spectrum as possible with what is available.

The views expressed by this supervisor seem to buttress Van der Westhuizen and de Wet's (2002: 188) argument that:

The supervisor plays a pivotal role in graduate training....(and) the main function of the supervisor is to guide the student to attain the aims of postgraduate study. In the process of achieving this, the supervisor fulfils a diversity of roles for which he/she can be trained. These roles range from official responsibilities, such as being an examiner of the dissertation, to a very personal role, such as promoting the student's career.

However, even if supervisors at UWC are aware of their role as quality assurors what is debatable is whether they all know enough about that role. The quotations above do not reflect that the supervisors are aware of all their roles and responsibilities. Findings from this research seem to suggest otherwise, indicating that there is a gap between what supervisors view as their roles and the role that the ideal supervisor must play. Perhaps because of this gap, there exists a mismatch between what supervisors do and what they are supposed, and thus lengthening the time to degree.

Literature on the role of the supervisor indicates that even though supervisors perceive their role as that of providing guide, advice and emotional and psychological support (Lessing and Schulze, 2003), one of their expectations is that they should be knowledgeable about the topic being researched by their students (Abiddin, 2006).

Chur-Hansen and McLean (2006) stated that supervisors have two distinct roles, namely teaching and assessing. As a teacher, the supervisor is expected to act as a mentor, a guide, an educator and a role model, while as an assessor the supervisor is meant to make judgments regarding whether the supervisee has passed or failed. In both ways, the supervisor is required to identify the abilities and strengths of his / her supervisees as well as the areas where they need improvement. According to van der Westhuizen and de Wet (2002), the mentor serves three primary functions. First, the mentor aids the student to acquire formal knowledge and technical skills. Second, he/she initiates the student into the rules, values and ethics of the relevant discipline. Third, he/she helps the student to develop selfconfidence.Nevertheless, as illustrated in the above quote, some experienced supervisors at UWC are aware of their roles and responsibilities as teachers, assessors and "pastors".

\subsection{Teaching role}

The teaching roles that supervisors at UWC play include mentoring, helping, directing, facilitating, inducting and assisting students. Some supervisors indicate that their role is to mentor research students and during this process they guide them in identifying the research topic in some cases. Supervisors guide their students on research approaches and on how to conduct fieldwork as well as drawing timelines for research projects. They also organize research workshops for their students with the view to help them develop research logic and sound conceptual frameworks. One of their teaching roles is to help students "demarcate" the scope of the research and to check if their students are meeting set criteria. Some supervisors regard it as their responsibility to guide students toward new knowledge or to equip them with new skills. Other supervisors believe their role is to train their students to think, reason, argue and write well.

\subsection{Assessment role}

Supervisors at UWC indicated that one of their roles is to provide critique to their students' work. In this regard, they work as a "sounding board" or "second eye", and provide feedback on all the key elements of the research process, including the adoption of appropriate research protocols, structuring of arguments, identification of research gaps, methodologies, use of appropriate laboratory analytical techniques, use of relevant literature, planning and adherence to university policy. In so doing supervisors provide a mechanism for quality check. Some supervisors hinted that even though their students 
have the prerogative to decide when they should submit their theses for examination, it is incumbent upon them to give the final approval before this process is considered.

\subsection{Pastoral role}

Interviews held with research supervisors at UWC indicate that the supervisor's pastoral role includes, giving advice to students, motivating and encouraging the students and "putting them on the right track". Supervisors argued that it is their role to help to build trust within the supervisory relationship and to provide emotional support to their students. Scholarly views about this finding are, however, divided. While one school of thought advocates for the supervisors provide advice, sympathy and encouragement outside the strict academic boundaries to the graduate students, the other school of thought strongly opposes this trend of events. The latter's claim is that supervisors should not involve themselves with students' personal problems because supervisors are not professionally trained counselors, have their own personal and professional problems and may cause more harm than good in trying to play the role of counselors (Spear, 2000). These divergent views are very intriguing because they provide fertile grounds for the further research into this important issue of pastoral role in the academic research supervision process.

However, the range of roles that different supervisors consider as important varies, indicating that there is no unified approach regarding the way academic researchers perceived their roles and responsibilities. While students may hold unrealistic expectations, the fact remains that they should receive sufficient guidance from their supervisors. In some cases students hold unrealistic expectations, which, for instance, makes them underestimate the amount of time that is needed to complete their research. Students may hold such unrealistic expectations, regardless of the fact that they may not have a strong research background. Delamont and Atkinson (1997) noted that in the UK there were two major barriers to a 4-year completion of doctoral studies, namely students' lack of background technical skills and knowledge in their discipline and the choice of topics, which were often too vast and unrealistically ambitious. This suggests that supervisors must balance their teaching, assessing and pastoral roles in order to improve the quality of supervision their students.

Before making any far-reaching recommendations, an examination of the approaches that supervisors adopt in their work experiences and the constraints that they face in doing so is required.

\subsection{Approaches that supervisors adopt and the constraints they experience}

A wide range of supervisory approaches have been adopted by supervisors across all the faculties within the institution. However, a unified approach within the Faculty of Science involves the use of a memorandum of understanding (MOU) which explains the roles and responsibilities of both the student and the supervisor. This approach has also been recently adopted by other Faculties. The MOUs indicate that these documents even spell out the frequency of supervision meetings, the number of leave days that research students are entitled to (where the students are involved in work study) and provide cover against the party that reneges on the agreement. Some supervisors see the MOU as a tool that keeps agreed parties constantly reminded of their roles and responsibilities. While the use of the MOU is gaining acceptance as a common approach to supervision and is slowly taking root within the university research community, interviews with different supervisors within the university indicate that supervisors have adopted other approaches as well.

In a number of cases, however, supervisors only have informal and unwritten agreements with their students. The argument presented by these supervisors is that supervision should be a flexible process in which the student must take the greater initiative in playing the dominant role in the research process. Such an approach is opposed by other supervisors who believe supervisors must be more assertive and employ the directive approach to supervision. However, none of these views take into account the dynamic nature of the relationship and the fact that research students may outgrow their supervisors in knowledge of the topic over the period of working on the thesis. In reality, while the supervisor may start off as the dominant partner, the relations may well change over time as the student becomes an equal or peer by virtue of his / her experience. Some supervisors maintained that the supervisor has to "bully the students in order to achieve results".

Another approach that supervisors adopt revolves around the use of models. For instance, one supervisor from another Faculty uses a thesis that was written by a former student to guide new students on how research should be conducted. However, findings from previous research reviewed for this study indicate that an important component of dealing with problems of inadequate supervision is the development of guidelines for evaluating the progress of postgraduate students (a form of memorandum of understanding between the student and the supervisor). Such a formal agreement or contract or code of contact can help solve relational problems (Hockey, 1996; van der Westhuizen and de 
Wet, 2002; Holtzhausen (2005). Such a written code or written contract serves the purpose of emphasizing the obligatory nature of the agreement and it also provides a means of formalizing the agreement, even though the contract can be flexible (Hockey, 1996).

The majority of supervisors at UWC, however, use the Writing Process Feedback (WPF) model where students are expected to complete and submit certain sections of their theses, usually chapters of the drafts, before they proceed to succeeding ones. The WPF is viewed by some supervisors as a mechanism that engages the supervisor to become part of the research process, while keeping the student focused on the task and to stay on track. Thus the student is nurtured and kept to the "grindstone". However, its usefulness has been questioned by some supervisors, indicating that there is no common ground regarding supervisory approaches. For instance, some supervisors maintained that the model is not compatible with their supervision styles.

One common variant of the WPF model is the innovative "lining approach" where the research questions are lined up with the adopted research approach, research design, research instruments and methods of data analysis. Other strategies used by supervisors to improve the quality of postgraduate research include validation of the methodologies that are employed in the research; use of a co-supervisor as a "sounding board" and to assist with supervision where the research is interdisciplinary or where the supervisor is a novice; preparation of regular progress reports by students; motivating students so as to elevate their expected standards of performance; using set standards or benchmarks to check the correctness of applied research procedures, especially where laboratory based analytical work is involved; and proofreading of theses and use of external examiners.

Pole (1998) notes that each university has its own set of guidelines for research students and often for research supervisors which clarify the roles and responsibilities of those involved and often establish what students can expect from their institutions. Regarding the use of a research manual as a basis for enhancing accountability, Morrison et al (2007) suggest that the manual should be distributed to both the student and the faculty advisor so that the responsibilities of each party are understood, including those related to the research timeline and the benchmarks that must be accomplished. McMorland et al (2003) noted that the need to pursue accountability amongst both students and staff has been central to research on doctoral experience at the University of Auckland.

At UWC, the option of a second or co-supervisor was widely recommended by the majority of supervisors. On the other hand, others felt that their feedback was a sufficient measure of quality assurance. This argument stemmed from the fact that supervisors mostly agree to supervising students whose research falls in their area of specialization. It can be inferred from Table 1 that about $83.5 \%$ of the supervisors interviewed in this study are dealing with students whose research directly or indirectly feeds into their own research.

Table 1: Number and $\%$ of supervisors whose students' research feeds into their own

\begin{tabular}{|l|c|c|}
\hline \multicolumn{1}{|c|}{ Response } & Number of respondents & \% of respondents \\
\hline All of them & 15 & 14.6 \\
\hline Most of them & 21 & 20.4 \\
\hline Some of them & 50 & 48.5 \\
\hline None of them & 13 & 12.6 \\
\hline Indifferent & 4 & 3.9 \\
\hline Total & 103 & 100 \\
\hline
\end{tabular}

Figure 1 specifies reasons that were given by supervisors while explaining why students' research projects feed into their own research.

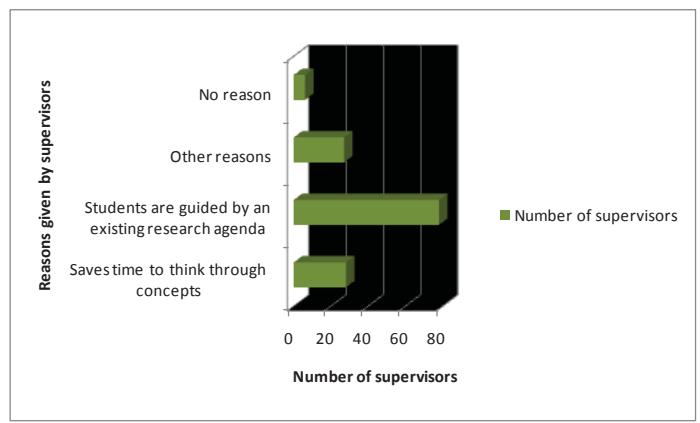

Figure 1: Reasons given for the close links between students' research projects and supervisors' own research 
The use of an existing research agenda provides a mechanism for producing publishable research while ensuring that the supervisor will spend less time on guiding the students, since the research will already have been designed. Less than $1 \%$ of the supervisors gave no explanation for the close links that exist between their research and the research that is being carried out by their students. Nevertheless, some supervisors are aware of the disadvantages of the close links that exist between their research and that of their students, even though a considerable number fail to appreciate this problem (Figure 2). The most notable disadvantages are that students' academic freedom is constrained and also that students will not be accorded the opportunity to develop as independent researchers.

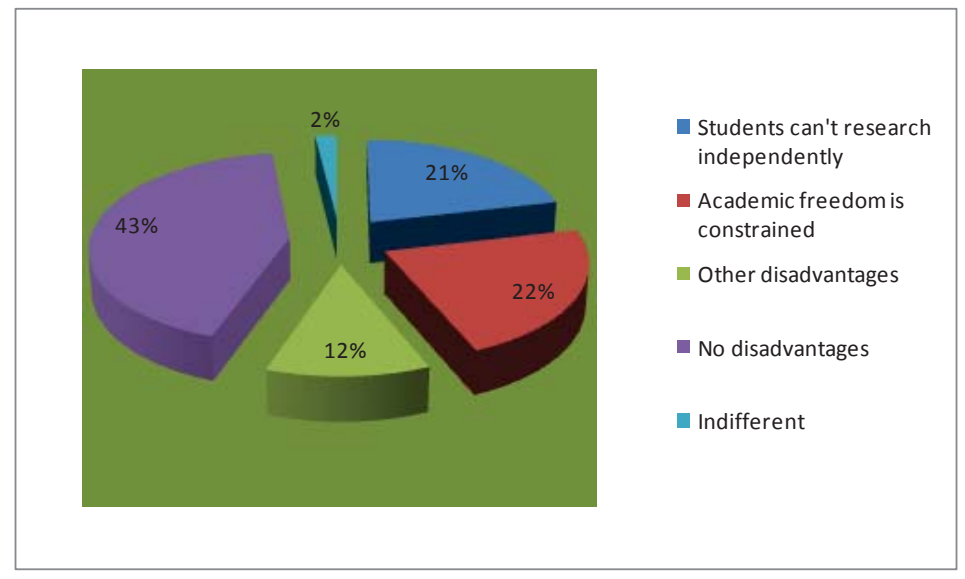

Figure 2: Percentage of supervisors who are aware of the disadvantages resulting from the close link between their research agendas and their students' projects.

In addition, responses from across faculties indicated that co-supervision can also allow a supervisor from another university to be appointed where collaboration flourishes between that university and UWC. Similar arrangements can also be made with industry. Such collaboration helps to fill the gaps around areas that the supervisor is not familiar with.

Although most supervisors attempt to address the issue of quality supervision with a view to improving their performance, the effectiveness of their roles is constrained by a number of factors. These factors fall into three categories, namely (supported by quotes from survey). Table 2 highlights supervisor- and student-related factors that constrain the effectiveness of postgraduate students

Table 2: Supervisor related and student related factors affecting the quality of supervision

\begin{tabular}{|c|c|}
\hline Supervisor-related factors & Student-related factors \\
\hline Lack of adequate quality control measures & $\begin{array}{l}\text { Communication difficulties, where students' first language is } \\
\text { not English }\end{array}$ \\
\hline $\begin{array}{l}\text { Lack of access to supervisors by students, as a result of the } \\
\text { engagement of the supervisor in other work, workshops and trips } \\
\text { abroad, including holidays }\end{array}$ & Lack of writing skills by students \\
\hline Lack of experience of how to supervise students & $\begin{array}{l}\text { Lack of geographical proximity, in cases where the distance } \\
\text { mode is applied as the main mode of instruction }\end{array}$ \\
\hline $\begin{array}{l}\text { Failure to recognize earlier students' circumstances that may hamper } \\
\text { research progress }\end{array}$ & Poor research design \\
\hline Lack of sufficient knowledge of the research topic by the supervisor & Lack of confidence by students \\
\hline $\begin{array}{l}\text { Disagreements between supervisors regarding the research, where } \\
\text { the student is co-supervised }\end{array}$ & $\begin{array}{l}\text { Some students lack adequate financial resources, leading to } \\
\text { situations where students seek employment to supplement } \\
\text { their incomes }\end{array}$ \\
\hline Lack of experience in adult learning by the supervisor & $\begin{array}{l}\text { Some students face transitional difficulties when they shift into } \\
\text { research areas with which they have vague theoretical } \\
\text { grounding. }\end{array}$ \\
\hline Lack of skills to develop the cognitive skills of students, particularly in & Lack of communication with supervisor \\
\hline
\end{tabular}




\begin{tabular}{|l|l|}
\hline the Science Faculty & \\
\hline $\begin{array}{l}\text { Lack of interpersonal skills, exemplified by cases where a supervisor } \\
\text { was often heard shouting at students by colleagues }\end{array}$ & \\
\hline $\begin{array}{l}\text { Heavy workloads, often resulting from resignations by colleagues who } \\
\text { leave to seek greener pastures, as a result of poor remuneration. }\end{array}$ & \\
\hline Lack of communication with students & \\
\hline $\begin{array}{l}\text { Defining the extent to which the supervisor should go in assisting the } \\
\text { students without compromising the originality of their work }\end{array}$ & \\
\hline
\end{tabular}

While some of the factors noted in Table 2 are evident only at the local level where they define the nature of the dyadic relationship between students and their supervisor most of them can be referred to as institutional.

\subsection{Institutional factors}

Although a wide range of constraints were cited, these were not matched with an equal measure of solutions. The majority of the solutions that supervisors suggested were mostly directed at student-related constraints. These include supervisory approaches, use of student support facilities within and outside the university, co-supervision and financial support.

\subsection{Supervisory approaches}

It was suggested by some supervisors that there was need to adopt a directive approach and use an enforceable MOU. In order to minimize conflicts in the supervisory relationship some supervisors maintained that it was necessary for them to select students whose behavioural attributes were compatible with their own. This approach on its own is a limitation because it perpetuates a shortage of research skills in fields where supervisors lack competency. A similar approach involves the use of the WPF model as a tool to develop the writing skills of the students. Students should be provided with research guides. An approach that has been adopted by one department is the use of "journal clubs" where students are involved in discussions centred on selected journal articles. This approach provides some form of induction into the community of research.

\subsection{Student support facilities}

While some interviewees felt that supervisors have the responsibility to train and equip their students with writing skills, others indicated that they refer those of their students who have language problems to the University Postgraduate Division ("PET") for assistance with research writing and statistical skills. PET has already developed research guides for postgraduate students and research supervisors. The guide for supervisors has been revised and updated as part of this project. Both the students' and supervisors' guides contain the technical requirements of postgraduate theses. To boost the confidence of the students, some supervisors proposed the use of conferences and workshops where students will have the opportunity to present papers and seminars and get feedback from peers and staff. Another confidence booster was that supervisors must only recruit students in areas in which they have expertise. Workshops and conferences give students the opportunity to learn from each other and from other peers. Such a situation can be complemented by group supervision as well as by offering support courses on research and open question and answer sessions during orientation week. One supervisor from one of the Faculty's recommended the formation of doctoral research support groups to create additional opportunities for tutoring and junior lecturing.

\subsection{Co-supervision}

The majority of the supervisors who were interviewed felt that co-supervision is beneficial to novice supervisors, and that it helps them to cope with the problems that they experience. It must be noted, however, that in lime survey results cosupervision was not highly prioritized, as discussed earlier. This is because some supervisors argued that there should be academic and social interaction between supervisors, so that supervisors can support each other as a committee rather than through mere bilateral co-supervision arrangements. Those who argue for the committee model maintained that the model creates epistemological spaces for people to grow within the discipline and provides scope for debates within the discipline about the theoretical and methodological advancements of researched fields, while simultaneously 
developing a supportive social environment that boosts the confidence of the student.

\subsection{Financial support}

It was noted by some supervisors that they often make attempts to engage their students in work study projects as a way of cushioning them from financial difficulties. Financial resources can be a limiting condition to time-to-degree and throughput. Results from the lime survey and indicated by supervisors indicate that the number of funded full-time PhD students who they have supervised complete their studies within five years is double that of non-funded part-time PhD students. In addition, the number of funded full-time students who complete their studies after five years is three times less than the number of non-funded part-time students. This therefore means availability of funding is a favourable condition for early completion. Supervisors also recommended that the university's financial planning system should be redesigned to make it more supportive of research activities.

\section{Conclusion}

The quality of postgraduate supervision takes a variety of forms and approaches and is largely determined by the research experience of the supervisors as well as a multiplicity of constraints. However, the major determinants of the quality of supervision within the institution include the manner in which supervisors understand and play out their roles, the supervisory approaches supervisors employ, access to student support facilities, including student financial support services. These factors are intertwined, in some cases not only reflecting the nature of the dyadic relationship between students and their supervisors but also rooted in the core management functions of the institution, including the way the institution is administered. This suggests that even if training workshops are introduced to equip supervisors with the skills of managing student matters and supervisory relationships the capacity to improve research supervision will remain unrealized unless the other conditions that affect both students and supervisors are addressed at institutional level. While training workshops would be of immense benefit to policy and decision makers within the institution any failure to provide financial support to the students who are admitted to postgraduate students won't bode well for improvements to time-todegree and throughput since students will be compelled to spend less time on their studies due to the need to take up employment to eke out a living. In conclusion, it is noted in this paper that quality of supervision is a critical element in both determining time-to-degree and throughput. However, quality of supervision is a complex phenomenon that is connected to panoply of conditions that have a tendency to vary both at institutional level and in specific individual relationships.

\section{Acknowledgment}

We are indebted to the critical reviewers of this paper and the comments made by the Editorial team of the Journal. We acknowledge the supervisors from all Faculties who participated in this study. We appreciate the funding provided by the Council for Higher Education (2009 grant). We thank UWC for support and ethical clearance to conduct the study. The views expressed in this paper are those of the authors and not of the funding institution nor the University of the Western Cape.

\section{References}

Abiddin, N. Z. (2006). Mentoring and Coaching: The Roles and Practices. Available at SSRN: http://ssrn.com/abstract=962231.

Abiddin, N. Z., Ismail, A., \& Ismail, A. (2011). Effective supervisory approach in enhancing postgraduate research studies. International Journal of Humanities and Social Science, 1(2), 206-217.

Blunt, R. J. S. and Conolly, J. (2006). Perceptions of mentoring: Expectations of a key resource for higher education. SAHIE 20 (2): 195208.

Boucher, C. \& Smyth, A. (2004). Up close and personal and personal reflections on our experience of supervising research candidates who are using personal reflective techniques. Reflective Practice 5 (3): 345-356.

Campbell, R.A. (2003). Preparing the next generation of scientists: The social progress of managing students. Social Studies of Science, 33(6), pp. 897-927

Chur-Hasen, A. \& Mclean, S. (2006). On being a supervisor: The importance of feedback and how to give it. Australian Psychiatry. 14 (1): 67-71.

Cohen, B. D. (2002). Surviving the PhD: Hints for Navigating the Sometimes Stormy Seas of Graduate Education in Political science Political Science and Politics 3: 585-588. 
Conrad, L. (2003). Five ways of enhancing the postgraduate community: Student perceptions of effective supervision and support. Griffith University, Brisbane, Australia. Retrieved from http:www.herdsa.or.au/wp-content/uploads/conference/2003/PDF /HERDSA57.pdf

Delamont, S, \& Atkinson, P. (1997). Critical mass and doctoral research: reflections on the Harris report. Studies in Higher Education, 22(3): 319-331

Denicolo, P. (2004) Assessing the PhD: a constructive view of criteria. Quality Assurance in Education. 11 (2), 84-91.

Doan, T., \& Yeoh, J. S. W. (2012). International research Student's perception of quality of supervision. International Journal of Innovative Interdisciplinary Research, 2012(3), 10-18.

Grant, B. \& Graham, A. (1999). Naming the game: reconstructing graduate supervision. Teaching in Higher Education, 4(1): 77-87.

Heath, T. (2002). A Quantitative Analysis of PhD Students. Views of Supervision; Higher Education Research and Development, .21 (1): $41-53$

Heng-Yu, K; Maria, K. E; Hsin-Te, Y \& Yi-Chia. C. (2008). Into the academy: preparing and mentoring international doctoral students. Education Tech Research Dev 56: 365-377.

Hockey, J. (1996). A contractual solution to problems in the supervision of PhD degreed in the UK. Studies in Higher Education 21(3): 359-376.

Holland, P. E. (1989). Stories of supervisors: tutorials in a transformative practice of supervision. Peabody Journal of Education. 66(3): 61-67.

Holtzhausen, S. M. (2005). The supervisor's accountability versus postgraduates' responsibility within the academic writing arena. South African Journal for Higher Education 19(1): 89-100

Humble, A. M., Solomon, C. R., Allen, K. R., Blaisure, K. R. \& Johnson, M. P. (2006). Feminism and mentoring of graduate students. Family Relations, 55: 2-15.

Jowett, V. \& Stead, R.(1994). Mentoring Students in Higher Education, Education and Training, 36(5):20-26

Lessing, A. C. \& Schulze, S. (2003). Postgraduate Supervision: Students and Supervisors Perceptions. Unisa, South Africa. Acta academia. 35 (3):161-184.

Mapesela, M. L. E. \& Wilkinson, A.C. (2005). The pain and gains of supervising postgraduate students from a distance: the case of six students from Lesotho. South Africa Journal of Higher Education, Special Issue: 1238-1254

McMorland, J.; Carroll, B.; Copas, S. \& Pringle, J. (2003). Enhancing the practice of PhD. supervisory relationships through first-and second-person action research/peer partnership inquiry. Qualitative Social Research, 4(2), pp. unnumbered.

Mendoza, P. (2007). Academic capitalism and doctoral student socialization: a case study. The Journal of Higher Education, 78 (1): $72-$ 96.

Morrison, J. L., Oladunjoye, G. T. \& Onyefulu, C. (2007). An assessment of research supervision: a leadership Model enhancing current practices in business management. Journal of Education for Business 82(4): 212-219.

Mullen, A. C. (2001). The need for a curricular writing model for graduate students. Journal of Further and Higher Education 25 (1): $118-$ 126

Murphy, N; Bain, J, D; \& Conrad, L. (2007). Orientations to Research Higher Degree Supervision. Higher Education.53:209-234.

Pole, C. (1998). Joint Supervision and the PhD :Safety net or panacea? Assessment and Evaluation in Higher Education 23(3): $259-271$

Rose, G. L. (2005). Group differences in graduate students' concepts of the ideal mentor. Research in Higher Education, 46(1): 53-80.

Salminen-Karlsson, M. \& Wallgren, R. (2007). The interaction of academic and industrial supervisors in graduate education: an investigation of industrial research schools. High Education, 56: 77-93.

Spear, R. H. (2000). Supervision of research students: Responding to student expectations. The Australian National University, Canberra.

Teye, J. K. (2012). Benefits, Challenges, and Dynamism of Positionalities Associated With Mixed Methods Research in Developing Countries Evidence From Ghana. Journal of Mixed Methods Research, 6(4), 379-391. doi:10.1177/1558689812453332

Thomas,K.,Willis, L.A. \& Davis, J. (2007) Mentoring minority graduate students: issues and strategies for institutions, faculty, and students. Equal Opportunities International 26 (3):78-192

Van der Westhuizen, P. C. \& De Wet, J. J. (2002). The training needs of supervisors of postgraduate students in the social sciences and humanities. South African Journal of Higher Education 16 (3): 185-195.

Wisker, G., Robinson, G., Trafford, V., Creighton, E. \& Warnes, M. (2003). Recognising and Overcoming Dissonance in Postgraduate Student Research. Studies in Higher Education,28 (1): 91-105.

Woodward-Kron, W. K. (2007). Negotiating meaning and scaffolding learning: writing support for non-English speaking background postgraduate students. Higher Education Research \& Development, 26:3, 253-268.

Wright, A; Murray, J.P. \& Geale, P. (2007). A phenomenographic study of what it means to supervise doctoral students. Academy of Management Learning \& Education, 6 (4) 589-474. 